\title{
Non-uniform response of regional cerebral blood flow to stimulation of cervical sympathetic nerve ${ }^{1}$
}

\author{
TAKENORI YAMAGUCHI AND ARTHUR G. WALTZ \\ From the Cerebrovascular Clinical Research Center, Department of Neurology, Mayo Clinic and Mayo Founda- $\frac{\overline{\bar{D}}}{\overline{\mathrm{N}}}$ \\ tion, and the Mayo Graduate School of Medicine (University of Minnesota), Rochester, Minnesota, U.S.A.
}

SUMMARY Regional cerebral blood flow (CBF) was measured by an autoradiographic method $\vec{\omega}$ in nine adult cats, using antipyrine $-{ }^{14} \mathrm{C}$ as a diffusible indicator. In seven of the cats, $\mathrm{CBF}$ measurements were made during stimulation of a cervical sympathetic trunk. Stimulation caused minor regional decreases of CBF in at least five of these seven cats. The decreases were non-uniform and $\omega$ occurred almost exclusively in cortical structures. Although constriction of cervical arteries probably accounts for some of the effects of sympathetic stimulation, the present study indicates that there also an effect on cerebral regulatory arterioles. However, there is no convincing evidence that $N$ function of the autonomic nervous system is necessary for the normal regulation of the cerebriक circulation.

The functions of the nerves that invest cerebral arterial blood vessels (Iwayama, Furness, and Burnstock, 1970; Nelson and Rennels, 1970) have not been determined as yet. Function of these nerves is not necessary for the normal regulation of the cerebral circulation (Waltz, Yamaguchi, and Regli, 1971). Although there is abundant evidence that stimulation of a cervical sympathetic trunk can constrict arterial vessels and decrease blood flow in the brain of an animal (Krog, 1964; Rosenblum, 1965; James, Millar, and Purves, 1969; D'Alecy and Feigl, 1970; Harper, Deshmukh, Rowan, and Jennett, 1971; Kobayashi, Waltz, and Rhoton, 1971), there often is a dissociation between changes of cortical arterial calibre and changes of cortical blood flow (Kobayashi et al., 1971). Sympathetic stimulation also can impair the responses of the cerebral vasculature to changes of arterial carbon dioxide tension $\left(\mathrm{PaCO}_{2}\right)$ (James et al., 1969; Harper et al., 1971; Kobayashi et al., 1971), but sympathetic denervation does not affect normal cerebral vascular regulatory responses (Waltz et al., 1971).

${ }^{2}$ This investigation was supported in part by Research Grant NB-6663 from the National Institutes of Health, Public Health Service.
Stimulation of the cervical sympathetic trunk ma influence the cerebral vasculature only secondarily, by constricting major arteries such as the carotid artery in the neck (Harper et al.,1971). If the decreases of cerebral blood flow (CBF) that are caused by sympathetic stimulation are due solely to constriction of major arteries, regional decreases of $\mathrm{CBF} \stackrel{\circ}{\varnothing}$ should be relatively uniform. If sympathetic stimula- $\stackrel{\varrho}{-}$ tion produces independent effects on cerebral $\overrightarrow{\overrightarrow{0}}$ arterioles via the nerves that invest them, regional variations of CBF decreases may occur and may be related to regional variations of the density of nerve fibres associated with fluorescent catecholamine $\overline{\bar{z}}$ products (Nielsen and Owman, 1967; Falck, ? Nielsen, and Owman, 1968). To determine uniformity $\frac{5}{3}$ of response, we measured CBF regionally throughout the brain, by an autoradiographic method (Landau, Freygang, Rowland, Sokoloff, and Kety, 1955; Reivich, Jehle, Sokoloff, and Kety, 1969; Blair and 윽 Waltz, 1970; Yamaguchi, Waltz, and Okazaki, 1971), $>$ during unilateral stimulation of a cervical sympathetic trunk.

\section{METHODS}

Nine adult cats were anaesthetized lightly with N pentobarbital $(25 \mathrm{mg} / \mathrm{kg})$ injected intrapleurally, and a $\sigma$ 
tracheostomy was made. In seven cats, the right cervical sympathetic trunk was exposed, separated from the accompanying vagus nerve, and identified by the ipsilateral pupillary reaction to electrical stimulation. The nerve was then cut, and the proximal stump of the distal segment was tied with silk suture for later identification.

In all cats, an arterial catheter was passed transfemorally to the abdominal aorta for monitoring mean systemic arterial blood pressure (MABP) with a strain gauge and polygraph and for drawing blood samples for measurement of $\mathrm{PaCO}_{2}, \mathrm{~Pa}_{2}, \mathrm{pH}$, and haematocrit value. A catheter was passed transfemorally to the inferior vena cava for the injection of a diffusible radioactive indicator. For all but cats 1 and 2, an arterial-venous shunt was established by connecting, through a three-way stopcock, a catheter placed transfemorally in the abdominal aorta to a catheter placed transfemorally in the inferior vena cava. Blood pressure in the shunt was monitored with a strain gauge and polygraph.

Each cat was paralysed with a minimal dose of $d$-tubocurarine (injected intravenously) and ventilated with a respirator. The ventilating mixture consisted of air to which was added small amounts of carbon dioxide and oxygen. $\mathrm{PaCO}_{2}$ was maintained constant between 30 and 36 torr (normal to slightly high for a cat); $\mathrm{Pa}_{2}$ was maintained constant between 95 and 135 torr.

In the seven cats with the cervical sympathetic trunk exposed, the nerve was stimulated by square-wave directcurrent impulses $(2 \mathrm{~V} ; 1.0 \mathrm{msec}$ duration; $60 \mathrm{~Hz}$ ). Pupillary response to the stimulation was confirmed. Once begun, stimulation was continued until the animal was killed. After two to four minutes of stimulation, ${ }^{14} \mathrm{C}$-labelled antipyrine was injected intravenously for measurement of regional CBF (Reivich et al., 1969; Blair and Waltz, 1970).

For each cat, a solution of antipyrine- ${ }^{14} \mathrm{C}$ (approximately $375 \mathrm{mCi}$ in $5 \mathrm{ml}$. isotonic saline) was injected into the inferior vena cava at a constant rate for one minute. During the injection, $0 \cdot 2 \mathrm{ml}$. blood was withdrawn every 10 seconds from the stopcock in the arterial-venous shunt, for measurement of the arterial concentration of the indicator (for cats 1 and 2, arterial blood was drawn from the catheter in the abdominal aorta). The circulation of blood then was stopped by rapid intravenous injection of a saturated solution of potassium chloride.

The brain was removed quickly (within 10 minutes) and frozen at -100 to $-150 \mathrm{C}$ in 2-methylbutane cooled with liquid nitrogen. After it was warmed to $-20 \mathrm{C}$ in a freezer for two to four days, the frozen brain was cut coronally into six to eight slices. Two serial sections, $20 \mu$ thick, were made from each slice in a cryostat, placed on glass slides, and dried on a hotplate.

The slides were put into a cassette so that the sections of brain faced the emulsion of $x$-ray film. Plastic disks containing known amounts of antipyrine- ${ }^{14} \mathrm{C}$ were also put into the cassette. After exposure for approximately 10 weeks, the film was developed and the optical densities of the autoradiographic images were measured with a densitometer. The amounts of antipyrine- ${ }^{14} \mathrm{C}$ in various regions of the brain were determined from a standard curve prepared from density values for the plastic disks.
Values for regional $\mathrm{CBF}$ were calculated by digital computer from the equation

$$
C t_{i}(T)=\lambda k_{i} \int_{0}^{T} C a_{i} e^{-k_{i}(T-t)} d t,
$$

in which $\mathrm{Ct}_{\mathrm{i}}(\mathrm{T})=$ concentration of antipyrine- ${ }^{14} \mathrm{C}$ in tissue at time $\mathrm{T}$ (one minute), $\lambda=$ blood-tissue partition coefficient ( $\lambda=1$ for antipyrine), $\mathrm{Ca}_{i}=$ arterial concentration of indicator, and $\mathrm{k}_{\mathrm{i}}($ with $\lambda=1)=\mathrm{CBF}$ value $(\mathrm{ml} . / \mathrm{g} / \mathrm{min})$.

Measurements of CBF were made from multiple sites in five regions of each of the two cerebral hemispheres: (1) superficial (exposed) cortex of the convexities of the hemispheres, excluding the temporal lobes and the inferior surfaces, (2) cortex from the same parts of the hemispheres but lying deep in sulci, (3) superficial and sulcal cortex from the temporal lobes and inferior surfaces of the hemispheres, (4) grey matter from the basal ganglia, largely the caudate and lenticular nuclei, and (5) white matter from the centra semiovales. The distinction between cortex of the basal parts of the hemisphere (temporal lobe and inferior surface) and cortex from other locations was made because preliminary analysis showed lower values for regional CBF of basal cortex.

The individual measurements obtained from each of the regions of each cerebral hemisphere were averaged. The mean value for each region was compared with the mean value for the same region of the opposite cerebral hemisphere by statistical analysis, to be certain that differences of CBF values were not due to random variability of individual measurements because of observer error or variations of true CBF.

\section{RESULTS}

There were no statistically significant differences between the regional CBF values obtained from the left and the right hemispheres of cats in which the cervical sympathetic trunk was not stimulated (cats 8 and 9); the maximal side-to-side difference was $0.03 \mathrm{ml} . / \mathrm{g} / \mathrm{min}$ (basal cortex, cat 9 and basal ganglia, cat 8) (Table). For the seven other cats, a side-to-side difference that was statistically significant and greater than $5 \%$ was considered indicative of a differential effect of sympathetic stimulation on CBF. Using these criteria, meaningful differential decreases of CBF occurred during sympathetic stimulation in seven regions in five animals: superficial cortex and sulcal cortex of cat 1 ; basal cortex of cat 2; superficial cortex of cat 4; sulcal cortex of cat 5 ; and sulcal cortex and basal cortex of cat 7 .

A typical autoradiograph is shown in the Figure. If less rigid criteria were used, differences of CBF were found for other regions as well. For example, if statistical significance were the only criterion, CBF values for superficial cortex and sulcal cortex of cat 3 would be considered lower on the side of stimulation. If large differences of regional CBF were considered meaningful regardiess of the results of statistical 
TABLE

EFFECT OF CERVICAL SYMPATHETIC STIMULATION ON REGIONAL CEREBRAL BLOOD FLOW

\begin{tabular}{|c|c|c|c|c|c|c|c|c|c|c|c|c|c|}
\hline \multirow[t]{3}{*}{ Cat } & \multirow{3}{*}{$\begin{array}{c}\text { Duration of } \\
\text { stim. (sec.) }\end{array}$} & \multirow{3}{*}{$\begin{array}{c}\text { Change of } \\
M A B P \\
(m m H g)\end{array}$} & \multirow[t]{3}{*}{ Side } & \multicolumn{10}{|c|}{$C B F(\mathrm{ml} / \mathrm{g} / \mathrm{min})$} \\
\hline & & & & \multicolumn{2}{|c|}{$\begin{array}{c}\text { Superficial } \\
\text { cortex }\end{array}$} & \multicolumn{2}{|c|}{$\begin{array}{l}\text { Sulcal } \\
\text { cortex }\end{array}$} & \multicolumn{2}{|c|}{$\begin{array}{l}\text { Basal } \\
\text { cortex }\end{array}$} & \multicolumn{2}{|c|}{$\begin{array}{c}\text { Basal } \\
\text { ganglia }\end{array}$} & \multicolumn{2}{|c|}{$\begin{array}{l}\text { Centrum } \\
\text { semiovale }\end{array}$} \\
\hline & & & & Mean & $S D$ & Mean & $S D$ & Mean & $S D$ & Mean & $S D$ & Mean & $S D$ \\
\hline 1 & 195 & $131-134$ & $\begin{array}{l}\text { Nonstimulated } \\
\text { Stimulated }\end{array}$ & $\begin{array}{l}1 \cdot 84 \\
1 \cdot 53^{*}\end{array}$ & $\begin{array}{l}0 \cdot 35 \\
0 \cdot 33\end{array}$ & $\begin{array}{l}1 \cdot 75 \\
1 \cdot 49^{*}\end{array}$ & $\begin{array}{l}0.34 \\
0 \cdot 28\end{array}$ & $\begin{array}{l}1.00 \\
1.04\end{array}$ & $\begin{array}{l}0.12 \\
0.12\end{array}$ & $\begin{array}{l}1 \cdot 25 \\
1 \cdot 21\end{array}$ & $\begin{array}{l}0.08 \\
0.14\end{array}$ & $\begin{array}{l}0.42 \\
0.36\end{array}$ & $\begin{array}{l}0.05 \\
0.04\end{array}$ \\
\hline \multirow[t]{2}{*}{2} & 160 & $106-111$ & Nonstimulated & 0.97 & $0 \cdot 13$ & 0.99 & $0 \cdot 12$ & 0.82 & 0.06 & 0.91 & $0 \cdot 11$ & 0.26 & 0.02 \\
\hline & & & Stimulated & 0.94 & $0 \cdot 15$ & 0.96 & $0 \cdot 14$ & $0.76 \dagger$ & 0.08 & 0.92 & 0.11 & 0.26 & 0.03 \\
\hline \multirow[t]{2}{*}{3} & 160 & $95-75$ & Nonstimulated & 0.64 & 0.05 & 0.69 & 0.06 & 0.54 & 0.11 & 0.72 & 0.08 & 0.20 & 0.02 \\
\hline & & & Stimulated & $0.61 \ddagger$ & 0.09 & $0.66 \ddagger$ & 0.06 & 0.56 & 0.07 & 0.74 & 0.06 & 0.19 & 0.02 \\
\hline \multirow[t]{2}{*}{4} & 135 & $135-141$ & Nonstimulated & $1 \cdot 72$ & $0 \cdot 23$ & $1 \cdot 64$ & 0.47 & $1 \cdot 29$ & 0.26 & $1 \cdot 64$ & 0.19 & $0 \cdot 33$ & 0.07 \\
\hline & & & Stimulated & $1.63 t$ & $0 \cdot 21$ & $1 \cdot 64$ & 0.23 & $1 \cdot 18$ & 0.22 & 1.47 & 0.18 & 0.32 & 0.04 \\
\hline \multirow[t]{2}{*}{5} & 240 & $72-69$ & Nonstimulated & 0.66 & 0.05 & 0.73 & 0.06 & 0.60 & 0.06 & 0.83 & 0.03 & 0.19 & 0.01 \\
\hline & & & Stimulated & 0.65 & 0.06 & $0.69 t$ & 0.05 & 0.59 & 0.07 & 0.79 & 0.03 & $0 \cdot 18$ & 0.02 \\
\hline \multirow[t]{2}{*}{6} & 150 & $108-104$ & Nonstimulated & 0.91 & 0.08 & 0.94 & 0.07 & 0.76 & $0 \cdot 12$ & 0.95 & 0.09 & 0.32 & 0.04 \\
\hline & & & Stimulated & 0.88 & 0.08 & 0.92 & 0.07 & 0.72 & 0.12 & 0.91 & 0.08 & 0.31 & 0.04 \\
\hline \multirow[t]{2}{*}{7} & 145 & $136-137$ & Nonstimulated & 0.94 & $0 \cdot 18$ & 0.99 & 0.08 & 0.77 & 0.09 & 0.95 & 0.07 & $0 \cdot 31$ & 0.02 \\
\hline & & & Stimulated & 0.90 & 0.08 & $0.92^{*}$ & 0.07 & $0.67 \ddagger$ & 0.06 & 0.86 & 0.12 & 0.30 & 0.02 \\
\hline \multirow[t]{2}{*}{8} & No & 173 & Left & 0.97 & 0.09 & 0.97 & 0.07 & 0.82 & $0 \cdot 10$ & $1 \cdot 00$ & 0.04 & 0.25 & 0.02 \\
\hline & stimulation & & Right & 0.96 & 0.08 & 0.99 & 0.08 & 0.82 & 0.11 & 1.03 & 0.04 & 0.26 & 0.03 \\
\hline \multirow[t]{2}{*}{9} & No & 141 & Left & $1 \cdot 07$ & 0.08 & 1.08 & $0 \cdot 10$ & 0.89 & $0 \cdot 11$ & $1 \cdot 30$ & 0.08 & 0.26 & 0.01 \\
\hline & stimulation & & Right & 1.06 & 0.09 & 1.08 & 0.09 & 0.92 & $0 \cdot 14$ & $1 \cdot 29$ & 0.12 & 0.26 & 0.02 \\
\hline \multirow{2}{*}{\multicolumn{3}{|c|}{$\begin{array}{l}\text { Mean for cats } \\
1 \text { through } 7\end{array}$}} & Nonstimulated & $1 \cdot 10$ & 0.49 & $1 \cdot 10$ & 0.42 & 0.83 & 0.25 & 1.04 & 0.31 & 0.29 & 0.08 \\
\hline & & & Stimulated & $1 \cdot 02$ & 0.40 & 1.04 & $0 \cdot 38$ & 0.80 & 0.23 & 0.99 & 0.26 & 0.27 & 0.07 \\
\hline
\end{tabular}

*For difference from nonstimulated side, $P<0.001 ;+P<0.05 ; \ddagger P<0.01$.

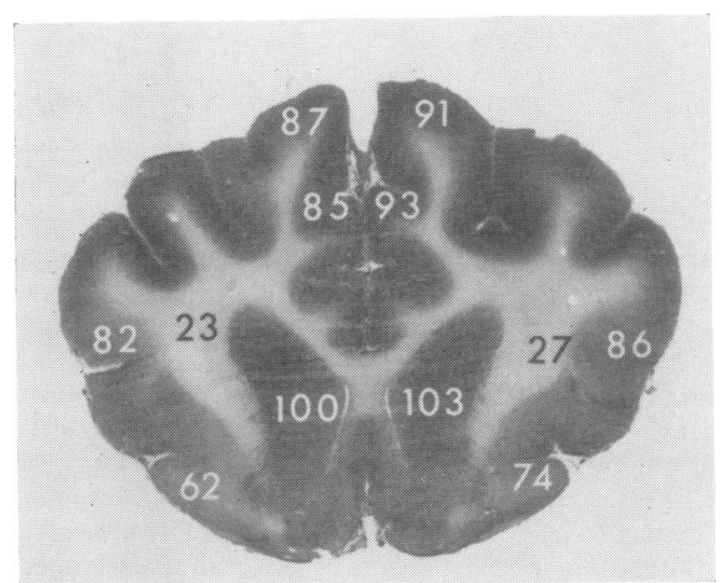

FIGURE. Autoradiograph of section of brain from cat 7 . $\mathrm{CBF}$ (indicated in $\mathrm{ml} . / \mathrm{g} / \mathrm{min} \times 100$ ) is directly related to density of autoradiographic image: darker regions are those with higher CBF. Right cerebral hemisphere, on same side as stimulated cervical sympathetic trunk, is at left in photograph.

analysis, CBF values for the centrum semiovale of cat 1 , the basal cortex and basal ganglia of cat 4 , and the basal ganglia of cat 7 would be considered lower on the side of stimulation. Regardless of the 0 criteria used, uniform unilateral decreases of CB were not demonstrated for any animal.

With rare exceptions, regional CBF values for the hemispheres on the side of stimulation were less than those for the opposite hemispheres. The means of the values from the different regions of the seven animals were less on the side of stimulation, but the differences did not reach statistical significance because of the small number of animals.

\section{DISCUSSION}

INTERPRETATIONS OF RESULTS Interpretation of these data must include consideration of the major limitation of the autoradiographic method: measurements of regional CBF can be made only once in any animal. Thus, regional CBF could not be measured both before and during stimulation of the cervical sympathetic trunk.

In cats, bilateral changes of cortical blood flow and of the calibre of superficial cortical arteries can result from unilateral sympathetic stimulation (Kobayashi et al., 1971), perhaps because of the or rete mirabile. Thus, comparing the CBF values from $N$ one hemisphere with those from the other may have N prevented recognition of meaningful decreases of 
CBF produced by sympathetic stimulation. For example, in cat 6 , stimulation may have caused relatively uniform bilateral decreases of $\mathrm{CBF}$. Similarly, there may have been bilateral decreases of CBF in other regions, such as the basal cortex of cat 1 , the superficial cortex of cat 3 , the sulcal cortex of cat 4 , the superficial cortex of cat 5 , and the superficial cortex of cat 7 .

Despite this difficulty, based on the necessary analysis of side-to-side differences, it is apparent that in at least five of the seven cats stimulation of a cervical sympathetic trunk caused decreases of CBF only in certain regions of the brain. There were no decreases (or lesser decreases) in other regions of the same cerebral hemispheres. The demonstration that sympathetic stimulation can produce non-uniform decreases of regional CBF provides the important information to be obtained from these data.

SIGNIFICANCE OF DATA If stimulation of a cervical sympathetic trunk causes decreases of CBF solely because of constriction of major arterial vessels, such as those in the neck (Harper et al., 1971), the decreases should be relatively uniform, at least within the territory of distribution of an individual branch of the circle of Willis (or the rete mirabile in animals that have such a structure). For regional decreases of CBF there must be regional differences of cerebral vascular resistance, caused by differential constriction or dilatation of regulatory arterioles. It is unlikely that constriction of a cervical artery would produce regional differences of metabolic activity or extracellular pH of the brain (Skinhøj, 1966; Wahl, Deetjen, Thurau, Ingvar, and Lassen, 1970) adequate to cause the non-uniform decreases of CBF demonstrated by this study.

The decreases of regional CBF produced by cervical sympathetic stimulation occurred almost exclusively in cortical structures. Of the 14 deeper regions that were measured (two from each of the animals), in three at most were there decreases of $\mathrm{CBF}$ and none was statistically significant. These findings provide additional evidence for an effect of sympathetic stimulation on regulatory arterioles, because the arterial vessels on the surface of the brain (supplying cortex) have a greater density of adrenergic nerve fibres than do the arterial branches penetrating the brain parenchyma (Nielsen and Owman, 1967; Falck et al., 1968).

Certain of the inconsistencies of the effects of stimulation of the cervical sympathetic trunk on $\mathrm{CBF}$, such as the occasional bilateral decreases of $\mathrm{CBF}$ and the relatively frequent dissociation between arteriolar calibre and CBF, can best be explained by constriction of cervical arteries (Harper et al.,
1971; Kobayashi et al., 1971). Other inconsistencies, such as the non-uniformity of decreases of $\mathrm{CBF}$ and the relatively more frequent decreases in cortical structures, can best be explained by differential constriction of regulatory arterioles. Although not conclusive, the present evidence suggests strongly that sympathetic activity produces constriction of both cervical arteries and cerebral regulatory arterioles and that decreases of CBF and impairment of vascular reactivity (James et al., 1969; Harper et al., 1971; Kobayashi et al., 1971) are caused by one or both of these vascular responses. However, the vascular responses to sympathetic stimulation are variable and inconsistent and are produced by non-physiological events. Thus, there is as yet no evidence to refute the concept that the autonomic nervous system has no function in the normal regulation of the cerebral circulation (Harper et al., 1971; Kobayashi et al., 1971; Waltz et al., 1971).

Technical, instrumentation, and analytic assistance were provided by Robert E. Anderson, Robert D. Ostrom, and the Mayo Clinic Computer Facility.

\section{REFERENCES}

Blair, R. D. G., and Waltz, A. G. (1970). Regional cerebral blood flow during acute ischaemia. Correlation of autoradiographic measurements with observations of cortical microcirculation. Neurology (Minneap.), 20, 802-808.

D'Alecy, L. G., and Feigl, E. O. (1970). Sympathetic cerebral vasoconstriction. (1971) Fed. Proc., 29, 520.

Falck, B., Nielsen, K. C., and Owman C. (1968). Adrenergic innervation of the pial circulation. Scand. J. clin lab. Invest., 22, Suppl. 102, VI: B.

Harper, A. M., Deshmukh, V. D., Rowan, J. O., and Jennett, W. B. (1971). Studies on possible neurogenic influences on the cerebral circulation. In Brain and Blood Flow: Proceedings of the 4th International Symposium on the Regulation of Cerebral Blood Flow, pp. 182-186. Edited by R. W. Ross Russell. Pitman: London,

Iwayama, T., Furness, J. B., and Burnstock, G. (1970). Dual adrenergic and cholinergic innervation of the cerebral arteries of the rat. Circulat. Res., 26, 635-646.

James, I. M., Millar, R. A., and Purves, M. J. (1969). Observations on the extrinsic neural control of cerebral blood flow in the baboon. Circulat. Res., 25, 77-93.

Kobayashi, S., Waltz, A. G., and Rhoton, A. L., Jr. (1971). Effects of stimulation of cervical sympathetic nerves on cortical blood flow and vascular reactivity. Neurology (Minneap.), 21, 297-302.

Krog, J. (1964). Autonomic nervous control of the cerebral blood flow in man. J. Oslo Cy Hosp., 14, 25-33.

Landau, W. M., Freygang, W. H., Jr., Rowland, L. P., Sokoloff, L., and Kety, S. S. (1955). The local circulation of the living brain; values in the unanesthetized and anesthetized cat. Trans. amer. neurol. Ass., 80, 125-129.

Nelson, E., and Rennels, M. (1970). Innervation of intracranial arteries. Brain, 93, 475-490.

Nielsen, K. C., and Owman, C. (1967). Adrenergic innervation of pial arteries related to the circle of Willis in the cat. Brain Res., 6, 773-776. 
Reivich, M., Jehle, J., Sokoloff, L., and Kety, S. S. (1969). Measurement of regional cerebral blood flow with antipyrine- ${ }^{14} \mathrm{C}$ in awake cats. J. appl. Physiol., 27, 296-300.

Rosenblum, W. I. (1965). Cerebral microcirculation: a review emphasizing the interrelationship of local blood flow and neuronal function. Angiology, 16, 485-507.

Skinhøj, E. (1966). Regulation of cerebral blood flow as a single function of the interstitial $\mathrm{pH}$ in the brain: a hypothesis. Acta neurol. scand., 42, 604-607.

Wahl, M., Deetjen, P., Thurau, K., Ingvar, D. H., and Lassen, N. A. (1970). Micropuncture evaluation of the importance of perivascular $\mathrm{pH}$ for the arteriolar diameter on the brain surface. Pfüger Arch. ges. Physiol., 316, 152-163.

Waltz, A. G., Yamaguchi, T., and Regli, F. (1971). Cerebral vascular reactivity after sympathetic denervation. In Brain and Blood Flow: Proceedings of the 4th International Symposium on the Regulation of Cerebral Blood Flow, (S) pp. 178-181. Edited by R. W. Ross Russell. Pitman: London.

Yamaguchi, T., Waltz, A. G., and Okazaki, H. (1971). Hyperemia and ischemia in experimental cerebral infarction: correlation of histopathology and regional blood flow. Neurology (Minneap.), 21, 565-578. 